\title{
Sonar-induced pressure fields in a post-mortem common dolphin
}

\author{
Kenneth G. Foote ${ }^{\text {a) }}$ \\ Woods Hole Oceanographic Institution, Woods Hole, Massachusetts 02543 \\ Mardi C. Hastings \\ G. W. Woodruff School of Mechanical Engineering, Georgia Institute of Technology, 126 Love Bldg., \\ 771 Ferst Drive, Atlanta, Georgia 30332-0405 \\ Darlene R. Ketten ${ }^{\text {b) }}$ \\ Biology Department, Woods Hole Oceanographic Institution, Woods Hole, Massachusetts 02543 \\ Ying-Tsong Lin \\ Woods Hole Oceanographic Institution, Woods Hole, Massachusetts 02543 \\ Joy S. Reidenberg \\ Center for Anatomy and Functional Morphology, Mail Box 1007, Mount Sinai School of Medicine, \\ 1 Gustave L. Levy Place, New York, New York 10029-6574 \\ Kent Rye \\ Department of the Navy, Naval Surface Warfare Center, Carderock Division, 9500 MacArthur Boulevard, \\ West Bethesda, Maryland 20817-5700
}

(Received 18 March 2011; revised 26 July 2011; accepted 8 December 2011)

\begin{abstract}
Potential physical effects of sonar transmissions on marine mammals were investigated by measuring pressure fields induced in a $119-\mathrm{kg}, 211-\mathrm{cm}-\mathrm{long}$, young adult male common dolphin (Delphinus delphis) cadaver. The specimen was instrumented with tourmaline acoustic pressure gauges used as receiving sensors. Gauge implantation near critical tissues was guided by intraoperative, high-resolution, computerized tomography (CT) scanning. Instrumented structures included the melon, nares, ear, thoracic wall, lungs, epaxial muscle, and lower abdomen. The specimen was suspended from a frame equipped with a standard 50.8-mm-diameter spherical transducer used as the acoustic source and additional receiving sensors to monitor the transmitted and external, scattered field. Following immersion, the transducer transmitted pulsed sinusoidal signals at 5, 7, and $10 \mathrm{kHz}$. Quantitative internal pressure fields are reported for all cases except those in which the gauge failed or no received signal was detected. A full necropsy was performed immediately after the experiment to examine instrumented areas and all major organs. No lesions attributable to acoustic transmissions were found, consistent with the low source level and source-receiver distances. ㄷ 2012 Acoustical Society of America. [DOI: 10.1121/1.3675005]
\end{abstract}

PACS number(s): 43.80.Ev, 43.80.Gx, 43.80.Nd, 43.80.Jz [JJF] Pages: 1595-1604

\section{INTRODUCTION}

Exposure to military sonar was postulated as the cause of a mass stranding of 12 beaked whales in Greece in 1996. ${ }^{1,2}$ Similar stranding events involving primarily Cuvier's beaked whale (Ziphius cavirostris) in the Bahamas and Madeira in $2000^{3,4}$ and in the Canary Islands in $2002^{5}$ coincided with naval exercises using mid-frequency sonars in the range $2.6-10 \mathrm{kHz} .{ }^{6}$ Subsequent mass stranding events coincident with the use of mid-frequency sonar in the Haro Strait near Washington State in $2003^{7,8}$ and off the coasts of Hawaii in $2004^{9}$ and North Carolina in $2005^{10}$ involved other species; however, medical examinations and necropsies of animals in these events found that they did not have injuries similar to those reported in beaked whales

\footnotetext{
a) Author to whom correspondence should be addressed. Electronic mail: kfoote@whoi.edu

b) Also at: Department of Otology and Laryngology, Harvard Medical School, Boston, MA, 02114.
}

that stranded in response to mid-frequency sonar transmissions. ${ }^{11-13}$ Understanding why beaked whales are particularly sensitive to mid-frequency sonar exercises is critical to managing and mitigating their potentially adverse effects. $^{4}$

Several hypotheses have been proposed about why beaked whales strand in response to sonar use, including acoustic resonance in the lungs and the formation of gas bubbles in major organs. The resonance hypothesis was eventually determined to be invalid because the probable amplitude of resonance in tissues was insufficient to produce damage. ${ }^{14}$ The formation of gas bubbles in potentially super-saturated tissues of deep-diving marine mammals could be induced by sound directly through rectified diffusion or indirectly through static diffusion due to animals surfacing too quickly. ${ }^{15-18}$ This hypothesis continues to be debated.

Research during the past 15 years to determine effects of noise on marine mammals ${ }^{19-21}$ has included studies to understand possible acoustic impacts of military sonar. 
These studies have included experiments on captive animals to determine onset of temporary threshold shifts and behavioral responses to loud sounds; controlled exposure experiments in the wild in which the sound incident at an animal is measured via D-tags; ${ }^{22-25}$ and the development of risk analysis models. ${ }^{26,27}$ Morphology-based models have attempted to take into account effects of tissue variations within marine mammals. $^{28-31}$

Direct measurements are difficult to accomplish, however, given the rarity and size of most adult beaked whales, with length of order $8.5 \mathrm{~m}$ for Cuvier's beaked whale and 3-5 $\mathrm{m}$ for most species of Mesoplodon. Measurements of sonar-induced pressure fields inside a beaked whale specimen could assist modeling in several decisive ways, such as revealing significant physical effects on critical tissues, provide data to validate morphological models, and assist in determining tissue material properties.

An alternative approach is pursued in this study, involving direct acoustic measurements on a toothed whale, i.e., odontocete, specimen of more manageable size. This was a 2.1-m-long specimen of a common dolphin (Delphinus delphis), which died of natural causes shortly after stranding and was stored in a freezer for a period of two months before controlled thawing and implantation of sensors. The specimen was ensonified by an external transducer operating in the upper half of the mid-frequency (MF) band, specifically at 5,7 , and $10 \mathrm{kHz}$. If the acoustic wavelength relative to organ size is a relevant factor for tissue injury, then the mentioned frequencies for the dolphin would correspond to lower frequencies for larger animals. These lower frequencies would be $1.3,1.8$, and $2.6 \mathrm{kHz}$ for an 8 -m-long animal in as much as scaling is applicable.

While performance of such measurements on a postmortem specimen without freezing and thawing might be preferred, the logistical obstacles to accomplishing such are formidable. It is believed that the freezing and thawing process did not impact the acoustic measurements in any substantive manner, consistent with the findings of McKenna et al. ${ }^{32}$

This paper describes the experiment with the common dolphin specimen. Details include specimen selection, preparation, and instrumentation with tourmaline pressure gauges; measurement of gauge locations by computerized tomographic (CT) scanning; sensor calibration; conduct of the acoustic measurements in a freshwater pond; and necropsy. Signal processing and data analysis methods are described. Results are expressed through the propagation times and magnitudes of signals received by the implanted sensors.

\section{MATERIALS}

\section{A. Specimen}

This work was conducted under permits number NMFS 932-1489-08 and number 493-1848/MA 130062 issued by National Marine Fisheries Service. Although no live animals were involved in this research, a prior review of the experimental protocol was required and subsequently approved by the Institutional Animal Care and Use Committee (IACUC) of the Biology Department of the Woods Hole Oceanographic Institution (WHOI).

Key criteria for selection of the specimen were the integrity, i.e., freshness, of the tissues, particularly airways, ears, and major abdominal organs, as well as being a manageable size for handling and transport. The specimen employed was a $119-\mathrm{kg}, 211-\mathrm{cm}$, young adult common dolphin (Delphinus delphis), which died of natural causes shortly after stranding on 8 December 2008 on a beach of Cape Cod, Massachusetts. This animal specimen was collected by the Cape Cod Stranding Network (CCSN) and transported within three hours to WHOI in Woods Hole, Massachusetts, where it was scanned, then stored in a freezer at $-20^{\circ} \mathrm{C}$ for a period of two months. The animal was stored by suspending it from the flukes in order to maintain organ and body conformation without compression. The quality of the tissues was verified at each stage: fresh, post-freezing, and post-thaw, to be certain the lungs and airways, inner ears, and abdominal organs were intact and within normal ranges. The specimen was registered at the WHOI Computerized Scanning and Imaging (CSI) Facility ${ }^{33}$ as CSI Reference No. D-del52, Field Reference No. CCSN05-205-Dd.

\section{B. Imaging}

A Siemens Somatom Volume Zoom spiral computerized tomography (CT) scanner at the WHOI CSI Facility ${ }^{33}$ was used for primary and post-instrumentation examinations of the specimen. Scanned data were stored in a standard Digital Imaging and Communications in Medicine (DICOM) format.

\section{Acoustic source and receiver}

The acoustic source was an International Transducer Corporation (ITC) Deep Water Omnidirectional Transducer model ITC-1032, referred to below as a spherical transducer. The external diameter of the active ceramic spherical transducer was $50.8 \mathrm{~mm}$; the external diameter with polyurethane encapsulation was $68.6 \mathrm{~mm}$. The transmitting voltage response increases from 100 to $147 \mathrm{~dB}$ re $1 \mu \mathrm{Pa} / \mathrm{V}$ at $1 \mathrm{~m}$ over the frequency band from 2 to $30 \mathrm{kHz}$. This rise is linear in the logarithmic domain, approximating $37 \mathrm{~dB}$ per decade in frequency.

The primary acoustic receiving sensor was a tourmaline pressure gauge designed and built at the Naval Surface Warfare Center (NSWC), Carderock Division, in West Bethesda, Maryland. The heart of the gauge was a cylindrical tourmaline crystal of diameter $1 / 8$ inch, thus about $3.2 \mathrm{~mm}$. When packaged, the gauge was a cylinder of diameter $4 \mathrm{~mm}$ and length $60 \mathrm{~mm}$. It was connected to a coaxial cable about 1.5-m long. These robust sensors are known for their applications to underwater blast measurements because of their fast rise time and relatively low charge sensitivity, which is approximately four orders of magnitude smaller than that of a standard laboratory piezoceramic hydrophone such as the Brüel and Kjær (B\&K) 8103 Miniature Hydrophone. The B\&K 8103, however, is approximately three times the diameter and ten times the mass of the tourmaline pressure gauge fabricated at NSWC. In addition, the NSWC tourmaline gauge is packaged in a sealed plastic tube filled with clear 
synthetic oil and directly integrated with a coaxial cable rather than encapsulated in a hard rubber terminated with a metal strain relief as in the B\&K 8103. Thus, the small size, light weight, and flexible packaging of the tourmaline pressure gauge makes it superior to the B\&K 8103 for implanting in biological systems with minimal disturbance to the surrounding tissues.

Following reception, the signals were amplified by several devices manufactured by PCB Piezotronics, Inc. (Depew, NY). Details on these and associated processing are given below in Sec. III D.

\section{Test facility}

The acoustic measurements on the common dolphin specimen were performed at the Explosion Test Pond facility of NSWC, Carderock Division. The pond is about $50 \mathrm{~m}$ in diameter, with an engineered, irregular bottom sloping to a maximum depth of about $8 \mathrm{~m}$. A well-equipped laboratory is located immediately beside the pond, facilitating both staging and observation of underwater experiments, including data recording. The facility has a subterranean well with ports for viewing underwater. Mobile cranes are available for manipulating and suspending gear and test objects in the pond.

\section{EXPERIMENT}

\section{A. Design}

The goal of the experiment was measurement of sonarinduced fields inside a post-mortem odontocete specimen through controlled sound-exposure. The target specimen, a common dolphin cadaver, was selected according to criteria of freshness, intactness, and appearance of good condition, and instrumented with implanted tourmaline pressure gauges. The whole specimen was imaged and the precise gauge placements were determined by computerized tomography (CT) scanning. The instrumented specimen was suspended from a frame together with external tourmaline pressure gauges and a precision spherical transducer to serve as an acoustic source. Following immersion, the specimen was ensonified with narrowband signals in the MF band. The acoustic measurements were repeated for each of three source locations. Immediately after the experiment, a necropsy was performed to determine possible impacts of the transmissions on tissues.

\section{B. Rehearsal}

In anticipation of the experiment, acoustic measurements were made on a $30-\mathrm{kg}$ pig carcass in 2008. Two tourmaline pressure gauges were surgically implanted. The carcass was then suspended from the same frame later used with the common dolphin specimen. Following immersion, it was ensonified by a spherical transducer operating at a sub-shock level. Quantitative signals were received in the gauge implanted in muscle tissue. These measurements, supplemented by performance measurements of the gauges in a small laboratory tank, established the capacity of the gauges to measure induced pressure fields in other carcasses, at least in soft tissues.
TABLE I. Tourmaline gauge placement in the common dolphin specimen. The Cable ID denotes the designation of the gauge signal in the PCB multichannel signal conditioner model 481.

\begin{tabular}{lccc}
\hline \hline Gauge No. & Cable ID & Location & Depth $(\mathrm{mm})$ \\
\hline 186 & $\mathrm{M}$ & Nares & 120 \\
112 & $\mathrm{H}$ & Left lung & 130 \\
187 & $\mathrm{~N}$ & Right lung & 110 \\
115 & $\mathrm{I}$ & Thorax & 120 \\
90 & $\mathrm{~K}$ & Melon & 40 \\
188 & $\mathrm{O}$ & Right ear & - \\
171 & $\mathrm{~J}$ & Abdomen & - \\
05 & $\mathrm{~F}$ & Epaxial muscle & 25 \\
\hline \hline
\end{tabular}

\section{Specimen preparation, morphometry, and instrumentation}

In preparation for the experiment, the common dolphin cadaver described in Sec. II A was removed from the storage freezer and thawed first in a chamber at $4^{\circ} \mathrm{C}$ and finally on a necropsy table with a continuous water drip over several days. Body temperatures were monitored during the thawing process via thermocouples inserted in the blow hole and rectum. CT scans were obtained when the dolphin was removed from the freezer and after thawing to verify that critical organs and structures were in appropriate condition for valid measurements. Scans were performed, as noted in Sec. II B, using a Siemens Somatom Volume Zoom CT Scanner, with both bone and soft tissue kernels, with a scanning protocol of $120 \mathrm{kV}, 234 \mathrm{~mA}$, and 350-mAs effective dose. After thawing and the second scan series, tourmaline pressure gauges were surgically implanted in the melon, nares, adjacent to the right ear, thoracic wall external to the right lung, right lung, left lung, epaxial muscle at the level of the dorsal fin, and intra-rectal, further described in Table I. Gauge placements are shown in Fig. 1. A detailed view for head gauges in the melon, nares, and ear is shown in Fig. 2. These virtual ray tracing (VRT) three-dimensional images also

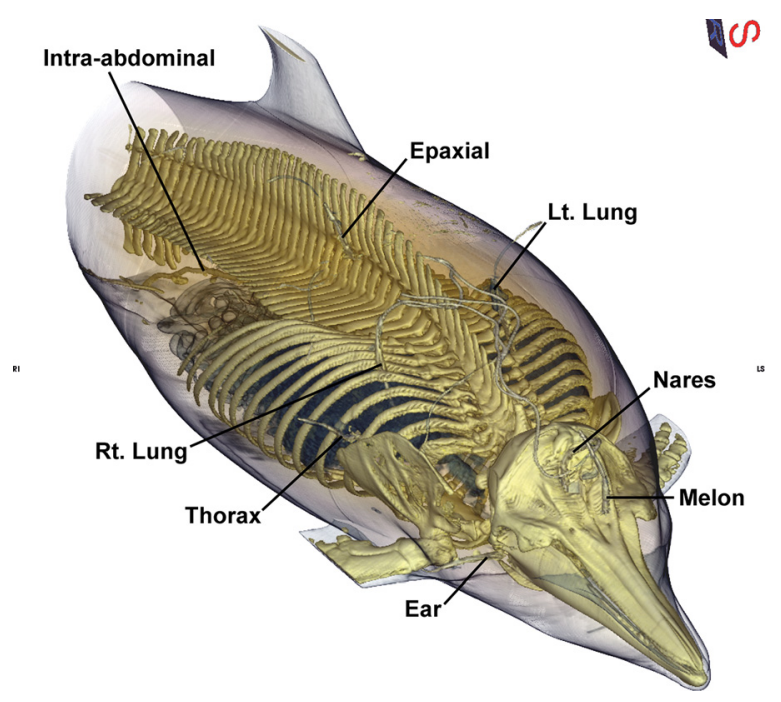

FIG. 1. (Color online) Gauge placements in the common dolphin specimen according to a virtual ray tracing (VRT) three-dimensional image, which also includes the lungs, skeleton, and skin for reference. 


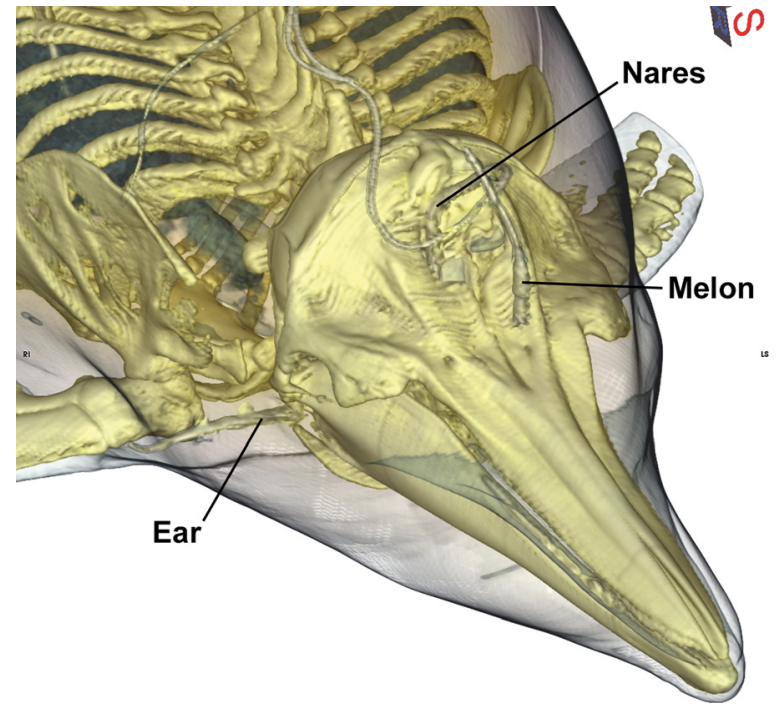

FIG. 2. (Color online) Detailed view of head gauge placements in the melon, nares, and ear in the common dolphin specimen based on the VRT three-dimensional image in Fig. 1.

include the lungs, skeleton, and skin for reference, and demonstrate segmentations that can be used for boundaryelement and finite-element analyses.

CT scan data were obtained in spiral scan protocol with images formatted at thicknesses of $1 \mathrm{~mm}$ before sensor implantation and $3 \mathrm{~mm}$ after sensor implantation. Segmented reformatted images were used to model surfaces and volumes quantitatively, thereby enabling tissue dimension measurements.

The instrumented specimen, Fig. 3, was transported by car in an insulated container with ice packs from WHOI to NSWC Carderock Division in West Bethesda, Maryland, on 2 February 2009. At Carderock, the specimen was transferred to a chiller until the day of the test. Blow hole and rectal temperatures prior to the experiment were 6.8 and $7.6^{\circ} \mathrm{C}$, respectively.

On the morning of the experiment, 4 February, the pecimen was removed from the chiller and the eight implanted gauges were tested in the laboratory beside the Explosion Test Pond. Three gauges were found to be dysfunctional and were replaced.

\section{Sensor calibration}

The pressure gauges were calibrated in-house at NSWC Carderock Division. Their approximate sensitivity is 0.225 picocoulombs $(\mathrm{pC})$ per pressure unit specified as one pound per square inch (psi), or $3.2610^{-5} \mathrm{pC} / \mathrm{Pa}$. Following reception, each signal was amplified by a PCB Model 422E01 In-line Charge Converter, with a nominal sensitivity of $100 \mathrm{mV} / \mathrm{pC}$. This signal was further amplified by a gain of 50 in a PCB Model 481 Multi-channel Signal Conditioner via a PCB Model 484 power unit to provide an overall measurement sensitivity of $0.163 \mathrm{mV} / \mathrm{Pa}$. Individual gauge calibrations and preamplifier gains are all slightly different but are adjusted for each gauge channel, i.e., equalized, so that the output of the multi-channel signal conditioner was expressed in consistent units of pressure.
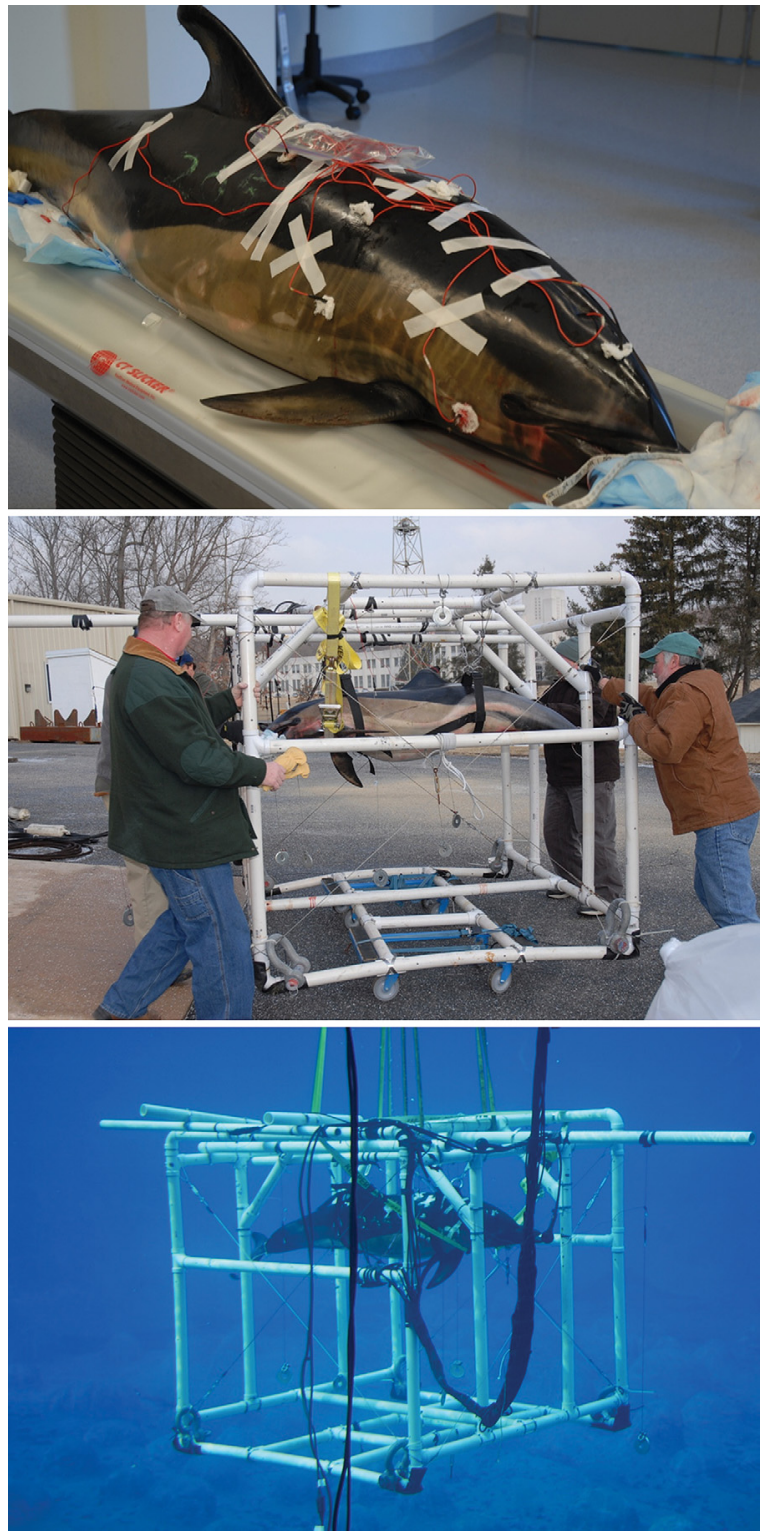

FIG. 3. (Color online) The experimental subject, a 119-kg, 211-cm-long common dolphin specimen, following implantation of tourmaline sensors at the WHOI CSI Facility, upper frame, suspended from a PVC-pipe frame at NSWC Carderock Division on 4 February 2009, middle frame, and immersed in the NSWC Explosion Test Pond facility for acoustic measurement, lower frame.

Subsequently, two different tourmaline pressure gauges with two different in-line charge converters used during the experiment were calibrated in a laboratory using similar signal conditioning and processing. All four combinations were examined. The frequency response over the range $0.25-10 \mathrm{kHz}$ was flat at all sound pressure levels. Measurements agreed with those of a calibrated reference hydrophone to within $\pm 3 \mathrm{~dB}$ for sound pressure levels from 110 to $130 \mathrm{~dB}$ re $1 \mu \mathrm{Pa}$ and to within $\pm 1 \mathrm{~dB}$ for sound pressure levels from 140 to $180 \mathrm{~dB}$ re $1 \mu \mathrm{Pa}^{34}$

\section{E. Rigging}

The specimen was suspended from a frame built of polyvinyl chloride (PVC) pipes, 5-cm diameter, shown in Fig. 3. These described a cubical volume of approximate 
side length $168 \mathrm{~cm}$. The pipes had holes at intervals to facilitate flooding upon immersion. Straps in the form of a harness were used to hold the specimen within the frame. The frame also supported external tourmaline pressure gauges and the ITC-1032 spherical transducer used as an acoustic source. Leads from both internal and external gauges were extended with underwater connectors and bundled, thence carried to the pond apron and adjacent laboratory for pre-amplification, digitization, and storage.

\section{F. Acoustic measurements}

On 4 February, the specimen was suspended in a PVCpipe frame and immersed in the fresh water Explosion Test Pond. The specimen depth was $2 \mathrm{~m}$, Fig. 3, where the temperature was $4^{\circ} \mathrm{C}$. Escaping air from the PVC pipes and the upper airways of the specimen was observed from the laboratory viewing ports immediately following immersion. When air bubbles were no longer observed, the specimen was exposed to multiple ensonifications from a single ITC1032 spherical transducer placed $10 \mathrm{~cm}$ in front of the rostrum. Initial measurements were performed to establish the data collection protocols. The transducer was excited at a pulse repetition rate of $4 \mathrm{~Hz}$ for a total of $6 \mathrm{~s}$ at each of three frequencies: 5,7 , and $10 \mathrm{kHz}$. The signal waveform was a 20-cycle sinusoidal burst with smooth rise and fall over two cycles. To avoid possible transient effects, data from the first second of each pinging sequence were ignored.

The frame with specimen was lifted back out of the pond and the source moved to the right of the specimen centerline as observed from above. The frame with specimen was immersed as before, with specimen again at 2-m depth. When air escaping from frame and upper airways was no longer observed, the measurements were repeated with the new source location. This process was repeated for a third source location, left of the specimen, but with different foreaft and up-down positions relative to those of the second source location. Details of the source locations are given in Table II. The cumulative immersion time of the specimen was about two hours.

Data were recorded simultaneously on 15 channels from six external sensors, eight implanted sensors, and source transducer, over a total of $5 \mathrm{~s}$ for each frequency and source location, with $4-\mathrm{Hz}$ pulse repetition frequency. Each signal was amplified by the same in-line charge converter and multi-channel signal conditioner as described above in Sec. III D. Digitization was performed at the output of the signal conditioner at a sampling rate of $100 \mathrm{kHz}$, and data were stored by means of custom-designed software on a hard disk.

TABLE II. Acoustic source locations external to the common dolphin specimen.

\begin{tabular}{ll}
\hline \hline Location & \multicolumn{1}{c}{ Description } \\
\hline 1 & $10 \mathrm{~cm}$ in front of rostrum \\
2 & $75 \mathrm{~cm}$ aft of tip of rostrum, $67 \mathrm{~cm}$ to right of specimen \\
& $\begin{array}{l}\text { centerline as viewed from above } \\
3\end{array}$ \\
& centerline as viewed from above, $35 \mathrm{~cm}$ above centerline \\
\hline \hline
\end{tabular}

J. Acoust. Soc. Am., Vol. 131, No. 2, February 2012
In addition, noise data were collected passively at the end of each series without source excitation.

One of the sensors, designated Cable B, was in the line of sight of the acoustic source, the ITC-1032 spherical transducer, at approximate 1-m range. Its data were used to determine the source level, presented in Table III.

\section{G. Necropsy}

Following the acoustic measurements, the specimen was removed from the suspension frame and transported by car to the Walter Reed Army Institute for Research (WRAIR), where a post-experiment necropsy was performed and samples collected for histological analyses. No tissue damage or pathologies attributable to acoustic transmissions were found in the specimen examinations.

\section{SIGNAL PROCESSING AND DATA ANALYSIS}

\section{A. Signal extraction}

The received signals were processed digitally. Initially, the complex envelope of each signal was extracted by multiplying by $\exp \left(-\mathrm{i} \omega_{0} \mathrm{t}\right)$, where $\omega_{0}=2 \pi \nu_{0}$ is the angular frequency at the carrier or center frequency $\nu_{0}$, and by applying a low-pass filter. ${ }^{35}$ An example of demodulation in the real domain is given by Lathi. ${ }^{36}$ The complex envelope can be considered as a complex demodulated signal. This was filtered further with a low-pass filter with optimal bandwidth determined in an ad hoc procedure to balance temporal sharpness achieved with a wide bandwidth against noise reduction achieved with a narrow bandwidth. The resultant bandwidth was equal to one-third of the carrier frequency. This was applied to the complex demodulated signal.

Finally, the filtered signal was processed by matched filtering $^{35}$ using a replica signal proportional to the complex demodulated transmit signal. Strictly speaking, this is a form of pulse compression, ${ }^{37}$ but under the described conditions of filtering a narrowband transmit signal, this is an excellent approximation, and the term "matched filtering" is retained. The constant of proportionality was the inverse of the rms amplitude of the transmit signal.

\section{B. Pressure reference}

Receiving sensor B was in sight of the acoustic source. Since the source, described in Sec. II C, was a spherical transducer with essentially omnidirectional beam pattern, the source level could be inferred from the signal at B. If the signal at $B$ was received with rms pressure amplitude $p_{1}$ at elapsed time $t_{1}$, then the distance $r_{1}$ between source and

TABLE III. Source levels of the ITC-1032 spherical transducer in units of decibels re $1 \mu \mathrm{Pa}$ at $1 \mathrm{~m}$.

\begin{tabular}{lcccc}
\hline \hline & & \multicolumn{3}{c}{ Frequency (kHz) } \\
\cline { 3 - 5 } & Source location & 5 & 7 & 10 \\
\hline 1 & Front & $158.6 \pm 0.3$ & $164.0 \pm 0.2$ & $169.6 \pm 0.1$ \\
2 & Right side & $157.5 \pm 0.3$ & $162.1 \pm 0.1$ & $172.1 \pm 0.1$ \\
3 & Left side & $155.3 \pm 0.2$ & $164.9 \pm 0.1$ & $168.9 \pm 0.1$ \\
\hline \hline
\end{tabular}

Foote et al:: Sonar-induced pressure in a post-mortem dolphin

1599 
sensor B is $\mathrm{ct}_{1}$, where $\mathrm{c}$ is the speed of sound. The rms pressure amplitude $\mathrm{p}_{0}$ at reference distance $\mathrm{r}_{0}=1 \mathrm{~m}$ from the source can be determined simply by equating the products of pressure amplitude and distance at the respective distances $r_{1}$ and $\mathrm{r}_{0}$, assuming negligible absorption. This is the present case, since the absorption coefficients at 5,7 , and $10 \mathrm{kHz}$ are $0.01,0.02$, and $0.04 \mathrm{~dB} / \mathrm{km}$, and $\mathrm{r}_{1} \approx 1 \mathrm{~m}$. Thus $\mathrm{r}_{0} \mathrm{p}_{0}=\mathrm{r}_{1} \mathrm{p}_{1}$, hence $\mathrm{p}_{0}=\mathrm{ct}_{1} \mathrm{p}_{1}$, and the source level is

$$
\mathrm{SL}=10 \log \left[\left|\mathrm{p}_{0}\right|^{2}\right]+120
$$

where the factor 120 renders the units as decibels relative to $1 \mu \mathrm{Pa}$ at $1 \mathrm{~m}$. The value assumed for $\mathrm{c}$ was $1422 \mathrm{~m} / \mathrm{s}$, corresponding to freshwater at about $4^{\circ} \mathrm{C}$.

\section{Statistical analysis}

Results of the narrowband analysis were expressed in units of pressure. These were normalized by reference to an effective source level of $0 \mathrm{~dB}$ re $1 \mu \mathrm{Pa}$ at $1 \mathrm{~m}$. The ordinary statistics of the mean and standard deviation were computed for each source location and receiving sensor. For all data sets except one, there were 20 pings, corresponding to a pinging rate of $4 \mathrm{~Hz}$ over $5 \mathrm{~s}$. In the exceptional case, that of the $5-\mathrm{kHz}$ signal with the source on the left side of the specimen, only four pings were registered directly on the transmit channel, although 20 pings were recorded on all other sensors.

\section{RESULTS AND DISCUSSION}

\section{A. General characteristics of received signals}

An overview of the collected data is given in Fig. 4 for the acoustic source on the right side of the specimen and a transmit signal centered at $7 \mathrm{kHz}$. Fifteen simultaneous time series are shown in toto. Fourteen of these correspond to signals received on the tourmaline pressure gauges. The fifteenth, marked Cable $\mathrm{Z}$, corresponds to the internally recorded transmit signal. Given that the transmit signal consisted of 20 cycles at the center frequency, the duration varied from $4 \mathrm{~ms}$ at $5 \mathrm{kHz}$ to $2 \mathrm{~ms}$ at $10 \mathrm{kHz}$. Since the total period of data recording is $5 \mathrm{~s}$, the information contained in Fig. 4 is necessarily limited. Further evidence of this is provided in Fig. 5, which expands three of the signals in Fig. 4. The transmit signal is shown as recorded internally on Cable $\mathrm{Z}$. The corresponding signals received in the epaxial muscle, Cable F, and melon, Cable K, are also shown, but following band-pass filtering, with bandwidth equal to one- third of the center frequency. Nonetheless, based on inspection of Fig. 4 alone, it is clear that the signals recorded on the six external gauges, Cables A, B, C, D. E, and G, were relatively strong, possibly excepting that of Cable $G$ in the acoustic shadow of the specimen.

Among the sensors implanted in the common dolphin, signals are readily observed on three of the eight implanted gauges, Cables F, K, and M, corresponding to the epaxial
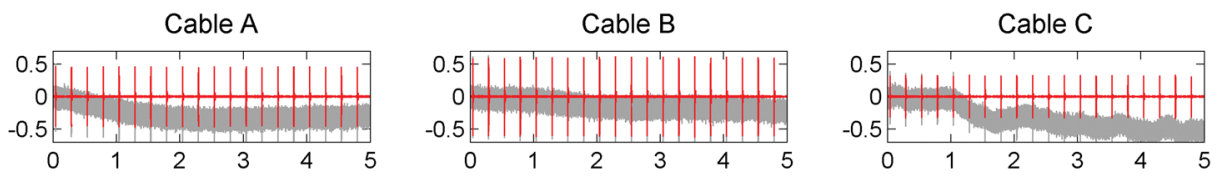

Cable D

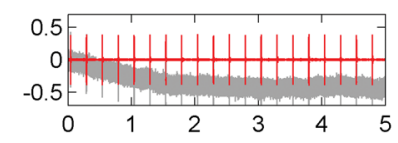

Cable E

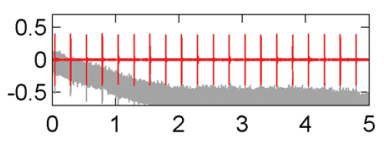

Cable F
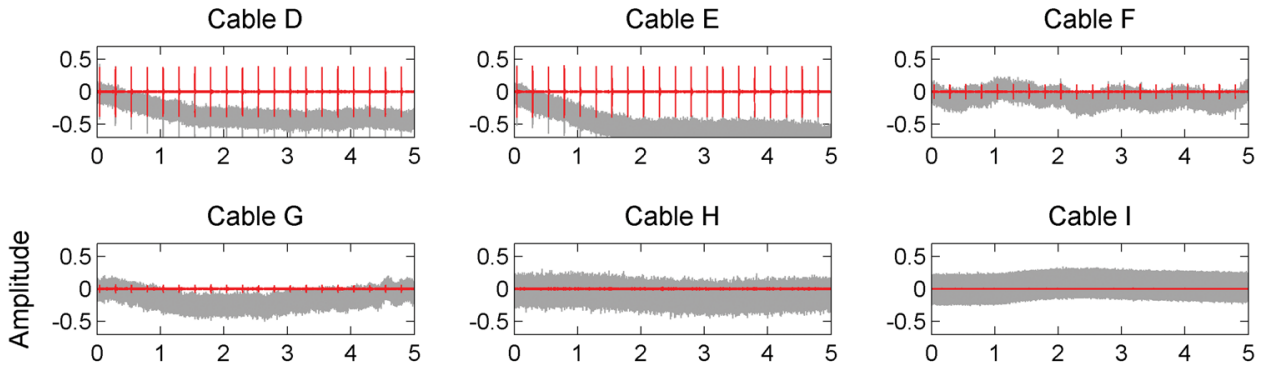

Cable
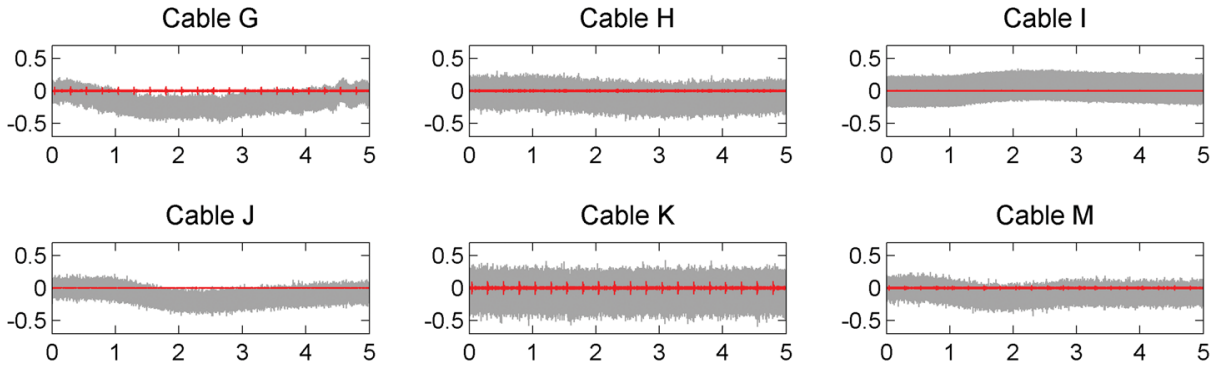

Cable N

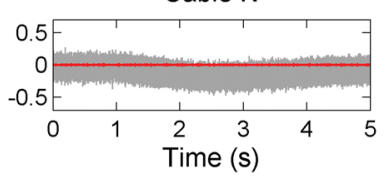

Cable $\mathrm{O}$
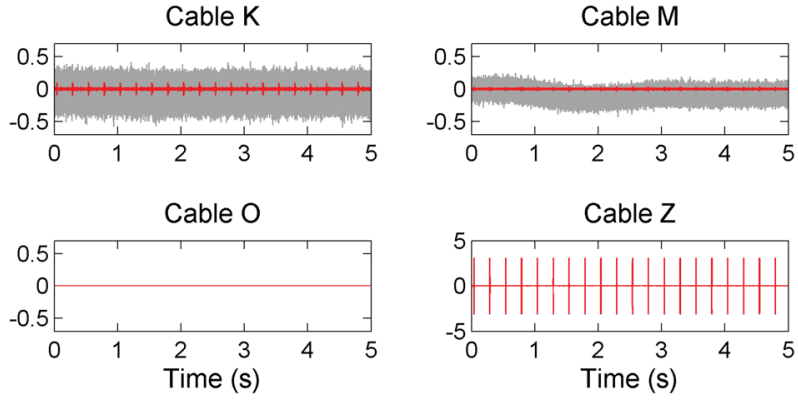

FIG. 4. (Color online) Overview of acoustic data collected during the experiment with the common dolphin specimen at NSWC Carderock Division on 4 February 2009 with the ITC-1032 spherical transducer on the right side of the specimen and transmit signal centered at $7 \mathrm{kHz}$. The total data collection time was $5 \mathrm{~s}$; the pulse repetition frequency was $4 \mathrm{~Hz}$. The total signal, including background noise, is shown in gray. The signal resulting from digital bandpass filtering with bandwidth equal to one-third of the center frequency is shown in red. Cables A, B, C, D, E, and G were connected to the external tourmaline sensors. Implanted tourmaline sensors were connected to Cable F for the epaxial muscle near the dorsal fin, Cable $\mathrm{H}$ for the left lung, Cable I for the thorax, Cable $\mathrm{J}$ for the abdomen, Cable $\mathrm{K}$ for the melon, Cable $\mathrm{M}$ for the nares, Cable $\mathrm{N}$ for the right lung, and Cable $\mathrm{O}$ for the right ear. Cable $\mathrm{Z}$ carried the electrical transmit signal without sensor connection. The displayed amplitudes are those of pressure, expressed in kilopascals, as measured at the face of all sensors excepting Cable $\mathrm{Z}$, for which the amplitude is expressed in volts. 

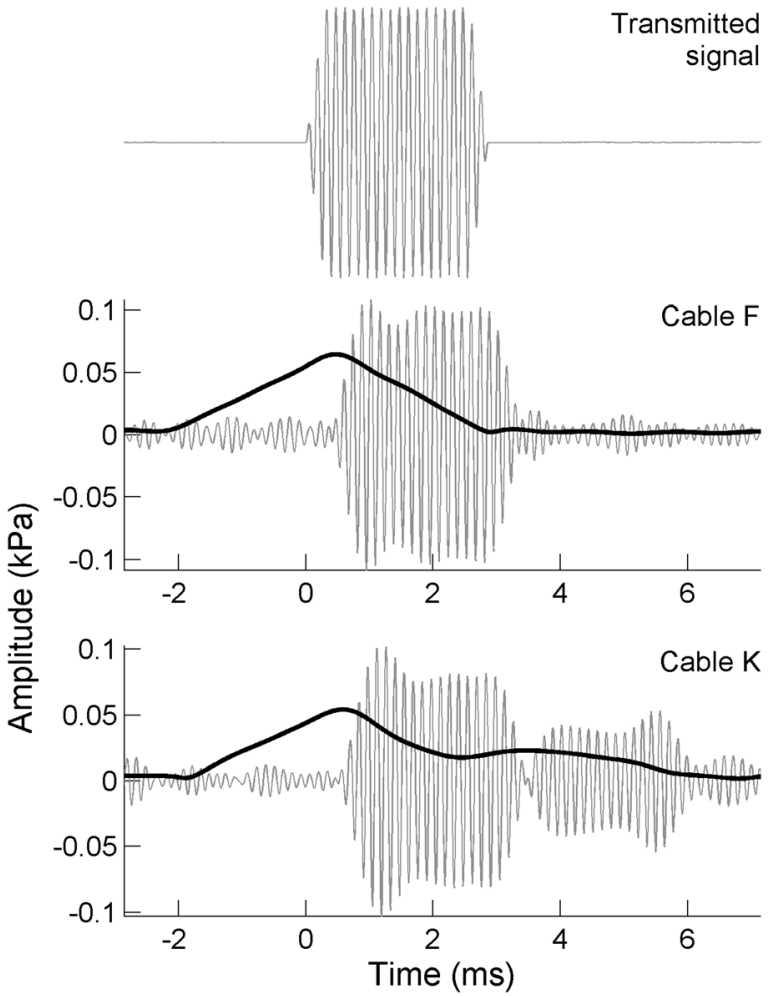

FIG. 5. Detail of processed signals derived from Fig. 4. The electronic transmit signal, shown in the upper frame, was recorded on the channel marked Cable Z. Its peak amplitude was $3 \mathrm{~V}$. It is shown here to provide an exact time reference for the corresponding signals received in the epaxial muscle, Cable F, and melon, Cable $\mathrm{K}$, which are shown in the middle and lower frames, respectively. The simple functions shown in the same middle and lower frames are the matched-filter outputs, derived according to the method in Sec. IV A.

muscle, melon, and nares, respectively, with those in the first two being relatively strong. Cable $\mathrm{O}$, implanted in the right ear, failed totally.

It is also clear that the signals were quite noisy. However, the sampling rate of $100 \mathrm{kHz}$, which is high relative to the center frequencies of 5,7 , and $10 \mathrm{kHz}$, enabled digital signal processing (DSP) to detect the noisy signals in many cases. For the overview in Fig. 4, the DSP consisted of band-pass filtering of the raw signal, with a bandwidth of one-third of the center frequency. Data collected at the other frequencies and source locations were analyzed in the same way, with similar findings to those reported here for the acoustic source on the right side of the specimen and 7-kHz transmit signal.

\section{B. Statistical characteristics of received signals}

Detailed, quantitative results are shown in Table IV. These were derived by DSP with complex envelope detection and matched filtering, as described in Sec. IV A, to determine the precise time of reception and magnitude of the received signals. This is illustrated in Fig. 5, where the matched filter output is superimposed on the band-pass filtered raw signal. The peak in the matched filter output marks the start of reception, and its height indicates the rms amplitude of the received signal.

The time of reception was measured as the time from the start of signal transmission by the acoustic source, the
TABLE IV. Statistical characteristics of the arrival time, Part A, and amplitude, Part B, of the signals in five tourmaline pressure gauges used as receiving sensors. These are based on the arrival time and amplitude of the matched-filter peak for the direct-path transmission in the external receiving sensor, designated Cable B, and sonar-induced pressure fields in the receiving sensors implanted in the epaxial muscle, Cable F, melon, Cable K, nares, Cable M, and right lung, Cable N. When the acoustic source was on the left side of the specimen and transmitted at $5 \mathrm{kHz}$, only four transmit signals were recorded on Cable $\mathrm{Z}$, hence only four received signals in the implanted sensors were analyzed. In all other cases, the entire set of 20 transmit and received signals were analyzed.

\begin{tabular}{|c|c|c|c|c|}
\hline \multirow{2}{*}{$\begin{array}{l}\text { Source } \\
\text { location }\end{array}$} & \multirow{2}{*}{$\begin{array}{l}\text { Receiver } \\
\text { location }\end{array}$} & \multicolumn{3}{|c|}{ A. Arrival time in milliseconds } \\
\hline & & $5 \mathrm{kHz}$ & $7 \mathrm{kHz}$ & $10 \mathrm{kHz}$ \\
\hline \multirow[t]{5}{*}{ Front } & B: External & $0.34 \pm 0.01$ & $0.37 \pm 0.01$ & $0.37 \pm 0.00$ \\
\hline & F: Epaxial muscle & $1.16 \pm 0.24$ & $2.79 \pm 0.09$ & $2.06 \pm 1.76$ \\
\hline & K: Melon & $0.23 \pm 0.02$ & $0.25 \pm 0.01$ & $0.33 \pm 0.00$ \\
\hline & M: Nares & - & $0.42 \pm 0.09$ & $0.62 \pm 0.04$ \\
\hline & N: Right lung & - & - & - \\
\hline \multirow[t]{5}{*}{ Right side } & B: External & $0.26 \pm 0.01$ & $0.25 \pm 0.00$ & $0.31 \pm 0.00$ \\
\hline & F: Epaxial muscle & $0.58 \pm 0.02$ & $0.49 \pm 0.01$ & $0.57 \pm 0.00$ \\
\hline & K: Melon & $0.80 \pm 0.05$ & $0.59 \pm 0.03$ & $0.67 \pm 0.00$ \\
\hline & M: Nares & $0.60 \pm 0.25$ & $0.73 \pm 0.05$ & $0.37 \pm 0.03$ \\
\hline & $\mathrm{N}$ : Right lung & - & $0.84 \pm 0.15$ & $0.75 \pm 0.04$ \\
\hline \multirow[t]{5}{*}{ Left side } & B: External & $0.28 \pm 0.01$ & $0.37 \pm 0.00$ & $0.35 \pm 0.00$ \\
\hline & F: Epaxial muscle & $0.86 \pm 0.10$ & $0.83 \pm 0.04$ & $0.80 \pm 0.02$ \\
\hline & K: Melon & $0.78 \pm 0.09$ & $1.08 \pm 0.03$ & $0.94 \pm 0.01$ \\
\hline & M: Nares & - & - & $1.04 \pm 0.19$ \\
\hline & N: Right lung & - & - & - \\
\hline \multirow{2}{*}{$\begin{array}{l}\text { Source } \\
\text { location }\end{array}$} & \multirow{2}{*}{$\begin{array}{l}\text { Receiver } \\
\text { location }\end{array}$} & \multicolumn{3}{|c|}{ B. Signal magnitude in decibels } \\
\hline & & $5 \mathrm{kHz}$ & $7 \mathrm{kHz}$ & $10 \mathrm{kHz}$ \\
\hline \multirow[t]{5}{*}{ Front } & B: External & $6.3 \pm 0.3$ & $5.6 \pm 0.1$ & $5.6 \pm 0.1$ \\
\hline & F: Epaxial muscle & $-20.3 \pm 1.0$ & $-20.9 \pm 0.9$ & $-25.7 \pm 0.8$ \\
\hline & K: Melon & $3.3 \pm 0.3$ & $3.9 \pm 0.2$ & $8.2 \pm 0.1$ \\
\hline & M: Nares & - & $-20.1 \pm 0.7$ & $-20.3 \pm 0.5$ \\
\hline & N: Right lung & - & - & - \\
\hline \multirow[t]{5}{*}{ Right side } & B: External & $8.6 \pm 0.3$ & $8.9 \pm 0.1$ & $7.2 \pm 0.1$ \\
\hline & F: Epaxial muscle & $-1.1 \pm 0.4$ & $-5.8 \pm 0.2$ & $-3.8 \pm 0.1$ \\
\hline & K: Melon & $-3.2 \pm 0.3$ & $-7.3 \pm 0.3$ & $-4.9 \pm 0.2$ \\
\hline & M: Nares & $-15.5 \pm 0.8$ & $-18.0 \pm 0.8$ & $-20.4 \pm 0.5$ \\
\hline & $\mathrm{N}$ : Right lung & - & $-20.5 \pm 1.0$ & $-21.7 \pm 0.4$ \\
\hline \multirow[t]{5}{*}{ Left side } & B: External & $8.0 \pm 0.3$ & $5.6 \pm 0.1$ & $6.1 \pm 0.1$ \\
\hline & F: Epaxial muscle & $-13.6 \pm 0.6$ & $-14.3 \pm 0.3$ & $-13.3 \pm 0.2$ \\
\hline & K: Melon & $-12.0 \pm 1.2$ & $-10.5 \pm 0.3$ & $-7.6 \pm 0.2$ \\
\hline & M: Nares & - & - & $-28.5 \pm 1.6$ \\
\hline & $\mathrm{N}$ : Right lung & - & - & - \\
\hline
\end{tabular}

ITC-1032 spherical transducer described in Sec. II C, to the start of reception. Pinging by the same transducer was periodic in an approximate but not precise sense. Given the short distances between the source transducer and receiving tourmaline pressure gauges, which were either implanted in the 211-cm-long dolphin or suspended from the frame, each received signal was analyzed relative to that actually transmitted and recorded in Cable Z. Thus, the reception time at a sensor was measured relative to the start of transmission of the respective signal on Cable $\mathrm{Z}$. 
The magnitude of the received signal was determined following the processing described in Sec. IV. The replica function used in the matched filtering was the respective signal on Cable Z. As mentioned in Sec. III D, each output signal of the multi-channel signal conditioner was expressed in calibrated pressure units, with the exception of the internally recorded electronic transmit signal on Cable $\mathrm{Z}$. This enabled the output to be expressed in both absolute and relative units. There was a choice here. Given measurement of the source level, with results in Table III, it was decided in Table IV to refer received signal magnitudes to a source level of $0 \mathrm{~dB}$ re $1 \mu \mathrm{Pa}$ at $1 \mathrm{~m}$. No range compensation for spreading loss was applied to the received signals.

\section{Physical interpretation}

The principal characteristics of the received signals are the reception time and magnitude. These are to be understood, or interpreted, relative to the detailed geometry of the experiment. The geometry is described by the location of the acoustic source, Table II; locations of the implanted receiving sensors, Table I and Figs. 1 and 2; and specimen anatomy specified by the CT images. The influence of the specimen is determined by its anatomy, namely tissue types, shapes, and sizes, and their physical properties.

The time of reception measures the time of flight of the transmit signal through the immersion medium between source and specimen and inside the specimen itself. At the transmit frequencies, the nominal acoustic wavelengths are $30 \mathrm{~cm}$ at $5 \mathrm{kHz}$ and $15 \mathrm{~cm}$ at $10 \mathrm{kHz}$. These wavelengths are of the order of or greater than the characteristic tissue dimensions. Propagation of the incident spherical wave inside the specimen is thus a complicated phenomenon involving transmission through and scattering at tissue interfaces and internal inhomogeneities, as well as absorption by the various tissues, and ultimately interference at the receiving sensors. This is evident from differences in the sound pressure level with internal location, reported in Table IV, for the same source location.

There is also a dependence on source location. The received signal in the melon was large when the source was in front of the rostrum, reflecting proximity, but it was also significant at the other source locations. However, the nares, reached through the blowhole, have a similar proximity to the source, but with very different characteristics. The received signal in the nares is highly attenuated, undoubtedly reflecting the absorption and other scattering properties of surrounding tissues. Received signal levels in the epaxial muscle also show a prominent dependence on the source location. The received signal in the right lung, when measured, is highly attenuated, like that in the nares. The received signal in the left lung was indistinguishable from noise.

The received signal magnitude is similarly influenced by internal propagation and scattering processes, including absorption. It may be imagined that the precise structure of the signal recorded at an implanted sensor contains information on these processes. This is illustrated in Fig. 6, where the matched-filter output for each of two received signals, at 5 and $7 \mathrm{kHz}$, are superimposed for each of two tissues, the epaxial muscle and melon. The ripple in the matched-filter

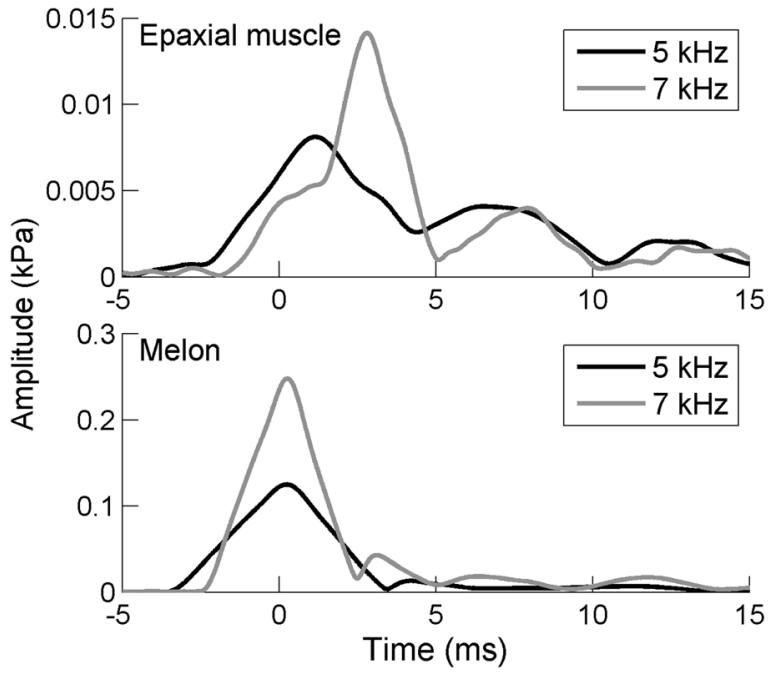

FIG. 6. Matched-filter outputs of 5- and 7-kHz signals received in the epaxial muscle and melon when the acoustic source was positioned in front of the rostrum. Each displayed matched-filter output is the average of the 20 corresponding outputs.

output for the epaxial muscle that precedes the peak may be significant for its suggestion of internal structure, a form of internal multipath.

There is also extraneous scattering due to the suspension apparatus and possible other scatterers in the vicinity of the specimen. In the reported experiment, the suspension frame was composed of 5-cm-diameter PVC pipes that were flooded, hence with diminished potential importance. The specimen was held in the pond at 2-m depth, precluding interference with water-surface reflections for the 2-ms transmit signal at $10 \mathrm{kHz}$. Possible interference with signals at $7 \mathrm{kHz}$ would be slight, and somewhat greater at $5 \mathrm{kHz}$.

To verify that possible residual bubbles from the frame or species did not influence the results, data collected at $10 \mathrm{kHz}$ within about $15 \mathrm{~min}$ of the first immersion were analyzed in the same way as data collected later in the measurement series. This was done for the tourmaline gauges implanted in the epaxial muscle and melon, as in the analysis underlying Fig. 6. Differences were very slight and were attributed to differences in sample size, since that of the first series consisted of just four pings rather than 20 of the later, fuller series.

In addition to revealing details about internal propagation and scattering characteristics, direct measurements of induced sound pressure fields have at least two other uses. They can be used to verify models describing sonar-induced fields inside marine mammals and to infer physical properties of tissues.

\section{Tourmaline pressure gauges}

A technical achievement of the present work has been demonstration of the usefulness of tourmaline pressure gauges for measurement of acoustic fields at sub-shock levels, supported by additional laboratory tests, ${ }^{34}$ also outlined above in Sec. III D. The tourmaline sensors used in the experiment were developed at NSWC, Carderock Division, where they have a long history of application to the measurement of pressures due to underwater explosions. In the 
reported experiment, the source sensors were used to measure pressure levels of order 10-1000 Pa, i.e., of order $10^{-4}-10^{-2}$ atm. This represents a significant extension of the useable operating range described by Rogers. ${ }^{38}$

\section{E. High-intensity effects}

It has been presumed here that induced acoustic effects are within the linear realm. This means that the linear wave equation applies, that acoustic fields superimpose, hence can be added linearly without multiplicative effects associated with nonlinearities. It has not been proven that nonlinear effects were absent. However, the source levels, represented in Table III, are modest and the internal sensors are not very close to the source, witness the quoted received pressure levels of order 10-1000 Pa.

Further evidence for the apparent absence of highintensity effects was obtained from the necropsy. Tissues were examined specifically for acoustic trauma. None was observed.

\section{CONCLUSIONS}

Protocols of an experiment to measure sonar-induced pressure fields inside a marine mammal have been developed. The required materials and methods, including signal processing, have been elaborated and illustrated for a postmortem young adult common dolphin that was instrumented with surgically implanted receiving sensors. Pressure fields induced by a proximate spherical transducer were measured in the epaxial muscle, melon, nares, and right lung for at least one of three acoustic source locations and for narrowband transmit signals with center frequencies of 5, 7, and $10 \mathrm{kHz}$. Measureable signals were not recorded in the left lung, thorax, and abdomen. The internal pressure fields have been characterized by the time of reception and magnitude of the received pressure field. Statistical measures of these have been tabulated.

There is considerable variability in the magnitude of received signals with respect to source location and frequency. This may be attributed partly to source location, but effects due to internal propagation and scattering including absorption are also likely.

Detailed morphometric data are available in the form of segmented reformatted images derived from CT scan data obtained in spiral-scan format. ${ }^{33}$ The images are formatted at thicknesses of $1 \mathrm{~mm}$ before sensor implantation and $3 \mathrm{~mm}$ after sensor implantation.

It is believed that finite-element models for sound propagation and scattering within marine mammals can be tested by reference to the kind of experiment reported here. It is also believed that essentially in vivo physical properties of some tissues can be inferred through a modeling exercise.

Tourmaline sensors can be used at sub-shock levels, as has been demonstrated in the experimental work.

\section{ACKNOWLEDGMENTS}

The contributions of J. A. Clark, deceased, are gratefully acknowledged. W. H. Lewis and other colleagues at NSWC are thanked for participating in the experiment. J. Arruda and
S. Cramer are thanked for diverse contributions. M. Parmenter is thanked for editorial assistance. Work supported by NOPP through ONR Grant No. N000140710992. Work at CSI additionally supported by ONR Grant No. N000140811231.

${ }^{1}$ A. Frantzis, "Does acoustic testing strand whales?" Nature 392, 29 (1998). ${ }^{2}$ G. L. D'Spain, A. D'Amico, and D. M. Fromm, "Properties of underwater sound fields during some beaked whale mass stranding events," J. Cetacean Res. Manage. 7, 223-238 (2006).

${ }^{3}$ NOAA, "Joint interim report Bahamas marine mammal stranding event of 15-16 March 2000," NOAA, December 2011. Available online at http:// www.nmfs.noaa.gov/pr/pdfs/health/stranding_bahamas2000.pdf (Last viewed 17 March 2011), 66 pp.

${ }^{4}$ T. M. Cox, T. J. Ragen, A. J. Read, E. Vos, R. W. Baird, K. Balcomb, J. Barlow, J. Caldwell, T. Cranford, L. Crum, A. D'Amico, G. D'Spain, A. Fernández, J. Finneran, R. Gentry, W. Gerth, F. Gulland, J. Hildebrand, D. Houser, T. Hullar, P. D. Jepson, D. Ketten, C. D. MacLeod, P. Miller, S. Moore, D. C. Mountain, D. Palka, P. Ponganis, S. Rommel, T. Rowles, B. Taylor, P. Tyack, D. Wartzok, R. Gisiner, J. Mead, and L. Benner, "Understanding the impacts of anthropogenic sound on beaked whales," J. Cetacean Res. Manage. 7, 177-187 (2006).

${ }^{5}$ Proceedings of the Workshop on Active Sonar and Cetaceans, European Cetacean Society's 17th Annual Conference, Las Palmas, Canary Islands, 8 March 2003, edited by P. G. H. Evans and L. A. Miller (European Cetacean Society Newsletter, No. 42-Special Issue, 2004), 84 pp.

${ }^{6}$ A. D'Amico, R. C. Gisiner, D. R. Ketten, J. A. Hammock, C. Johnson, P. L. Tyack, and J. Mead, "Beaked whale strandings and naval exercises," Aquat. Mamm. 35, 452-472 (2009).

${ }^{7}$ S. A. Norman, S. Raverty, S. B. McLellan, A. Pabst, D. Ketten, M. Fleetwood, J. K. Gaydos, B. Norberg, L. Barre, T. Cox, B. Hanson, and S. Jeffries, "Multidisciplinary investigation of stranded harbor porpoises (Phocoena phocoena) in Washington State with an assessment of acoustic trauma as a contributory factor (2 May-2 June 2003)," NOAA Technical Memorandum Report No. NMFS-NWR-34, U.S. Dept. of Commerce (2004), 120 pp.

${ }^{8}$ National Marine Fisheries Service, "Assessment of acoustic exposures on marine mammals in conjunction with USS Shoup active sonar transmissions in the Eastern Strait of Juan de Fuca and Haro Strait, Washington, 5 May 2003," Office of Protected Resources, 21 January 2005. Available online at http://www.nmfs.noaa.gov/pr/pdfs/acoustics/assessment.pdf (Last viewed 17 March 2011), 13 pp.

${ }^{9}$ B. L. Southall, R. Braun, F. M. D. Gulland, A. D. Heard, R. W. Baird, S. M. Wilkin, and T. K. Rowles, "Hawaiian melon-headed whale (Peponocephala electra) mass stranding event of July 3-4, 2004," NOAA Technical Memorandum Report No. NMFS-OPR-31, 73 pp. (2006).

${ }^{10}$ A. A. Hohn, D. S. Rotstein, C. A. Harms, and B. L. Southall, "Report on marine mammal unusual mortality event UMESE0501Sp: Multispecies mass stranding of pilot whales (Globicephala macrorhynchus), minke whale (Balaenoptera acutorostrata), and dwarf sperm whales (Kogia sima) in North Carolina on 15-16 January 2005," NOAA Technical Memorandum Report No. NMFS-SEFSC-537, 222 pp. (2006).

${ }^{11}$ L. Freitas, "The stranding of three Cuvier's beaked whales Ziphius cavirostris in Madeira archipelago-May 2000," in Proceedings of the Workshop on Active Sonar and Cetaceans, European Cetacean Society's 17th Annual Conference, Las Palmas, Canary Islands, 8 March 2003, edited by P. G. H. Evans and L. A. Miller (European Cetacean Society Newsletter, No. 42-Special Issue, 2004), pp. 28-32.

${ }^{12}$ D. R. Ketten, "Beaked whale necropsy findings for strandings in the Bahamas, Puerto Rico, and Madeira, 1999-2002," Woods Hole Oceanographic Institution Technical Report No. WHOI- 2005-09, (2005), 38 pp. Available online at http://www.whoi.edu/csi/images/WHOI-2005-09.pdf (Last viewed 17 March 2011).

${ }^{13}$ A. Fernández, J. F. Edwards, F. Rodriguez, A. Espinosa de los Monteros, P. Herraez, P. Castro, J. R. Jaber, V. Martin, and M. Arbelo, "Gas and fat embolic syndrome' involving a mass stranding of beaked whales (family Ziphiidae) exposed to anthropogenic sonar signals," Vet. Pathol. 42, 446-457 (2005).

${ }^{14}$ NOAA, "Report of the workshop on acoustic resonance as a source of tissue trauma in cetaceans. April 24 and 25, 2002 Silver Spring, MD," NOAA, November 2002. Available online at http://www.nmfs.noaa.gov/ pr/pdfs/acoustics/cetaceans.pdf (Last viewed 17 March 2011), 19 pp.

${ }^{15}$ L. A. Crum and Y. Mao, "Acoustically enhanced bubble growth at low frequencies and its implications for human diver and marine mammal safety," J. Acoust. Soc. Am. 99, 2898-2907 (1996). 
${ }^{16}$ D. S. Houser, R. Howard, and S. Ridgway, "Can diving-induced tissue nitrogen supersaturation increase the chance of acoustically driven bubble growth in marine mammals?" J. Theor. Biol. 213, 183-195 (2001).

${ }^{17}$ P. D. Jepson, M. Arbelo, R. Deaville, I. A. P. Patterson, P. Castro, J. R. Baker, E. Degollada, H. M. Ross, P. Herráez, A. M. Pocknell, F. Rodríguez, F. E. Howie, A. Espinosa, R. J. Reid, J. R. Jaber, V. Martin, A. A. Cunningham, and A. Fernández, "Gas-bubble lesions in stranded cetaceans," Nature 425, 575-576 (2003).

${ }^{18}$ S. A. Rommel, A. M. Costidis, A. Fernández, P. D. Jepson, D. A. Pabst, W. A. McLellan, D. S. Houser, T. W. Cranford, A. L. van Helden, D. M. Allen, and N. B. Barros, "Elements of beaked whale anatomy and diving physiology and some hypothetical causes of sonar-related stranding," J. Cetacean Res. Manage. 7, 189-209 (2006).

${ }^{19}$ National Research Council (NRC), Marine Mammals and Low-Frequency Sound (National Academies Press, Washington, DC, 2000), 160 pp.

${ }^{20}$ National Research Council (NRC), Ocean Noise and Marine Mammals (National Academies Press, Washington, DC, 2003), 204 pp.

${ }^{21}$ National Research Council (NRC), Marine Mammal Populations and Ocean Noise: Determining When Noise Causes Biologically Significant Effects (National Academies Press, Washington, DC, 2005), 142 pp.

${ }^{22}$ M. P. Johnson and P. L. Tyack, "A digital acoutic recording tag for measuring the response of wild marine mammals to sound," IEEE J. Ocean. Eng. 28, 3-12 (2003).

${ }^{23}$ P. L. Tyack, M. Johnson, N. A. Soto, A. Sturlese, and P. T. Madsen, "Extreme diving of beaked whales," J. Exp. Biol. 209, 4238-4253 (2006).

${ }^{24}$ Woods Hole Oceanographic Institution: Marine Mammal Behavior Laboratory: Peter Tyack's Laboratory, "DTAG: A Digital Acoustic Recording Tag," 27 January 2010. Available online at http://www.whoi.edu/ page.do?pid $=39337$ (Last viewed 19 July 2011).

${ }^{25}$ P. L. Tyack, W. M. X. Zimmer, D. Moretti, B. L. Southall, D. E. Claridge, J. W. Durban, C. W. Clark, A. D’Amico, N. DiMarzio, S. Jarvis, E. McCarthy, R. Morrissey, J. Ward, and I. L. Boyd, "Beaked whales respond to simulated and actual Navy sonar," PLoS ONE 6(3), 15 pp. (2011).

${ }^{26}$ W. T. Ellison, K. Weixel, and C. W. Clark, "An acoustic integration model (AIM) for assessing the impact of underwater noise on marine wildlife (A)," J. Acoust. Soc. Am. 106, 2250 (1999).
${ }^{27}$ H.-J. Shyu and R. Hillson, "A software workbench for estimating the effects of cumulative sound exposure in marine mammals," IEEE J. Oceanic Eng. 31, 8-21 (2006).

${ }^{28}$ J. L. Aroyan, "Three-dimensional modeling of hearing in Delphinus delphis," J. Acoust. Soc. Am. 110, 3305-3318 (2001).

${ }^{29}$ P. Krysl, T. W. Cranford, S. M. Wiggins, and J. A. Hildebrand, "Simulating the effect of high-intensity sound on cetaceans: Modeling and a case study for Cuvier's beaked whale (Ziphius cavirostris)," J. Acoust. Soc. Am. 120, 2328-2339 (2006).

${ }^{30}$ W. M. X. Zimmer and P. L. Tyack, "Repetitive shallow dives pose decompression risk in deep-diving beaked whales," Marine Mammal Sci. 23, 888-925 (2007).

${ }^{31}$ T. W. Cranford, P. Krysl, and J. A. Hildebrand, "Acoustic pathways revealed: Simulated sound transmission and reception in Cuvier's beaked whale (Ziphius cavirostris)," Bioinspir. Biomim. 3(1), 10 pp. (2008).

${ }^{32}$ M. F. McKenna, J. A. Goldbogen, J. St. Leger, J. A. Hildebrand, and T. W. Cranford, "Evaluation of postmortem changes in tissue structure in the bottlenose dolphin (Tursiops truncatus)," Anat. Rec. 290, 1023-1032 (2007).

${ }^{33}$ CSI - Computerized Scanning and Imaging Facility of Woods Hole Oceanographic Institution, Woods Hole, MA, http://csi.whoi.edu/ (Last viewed 20 July 2011).

${ }^{34}$ J. Morales, A. Kale, and M. Hastings, "Performance of tourmaline hydrophones at low- and midfrequencies (A)," J. Acoust. Soc. Am 129, 2643 (2011).

${ }^{35}$ W. Munk, P. Worcester, and C. Wunsch, Ocean Acoustic Tomography (Cambridge University Press, Cambridge, England, 1995), 433 pp.

${ }^{36}$ B. P. Lathi, Signals, Systems, and Communication (Wiley, New York, 1965), $607 \mathrm{pp}$.

${ }^{37}$ D. Chu and T. K. Stanton, "Application of pulse compression techniques to broadband acoustic scattering by live individual zooplankton," J. Acoust. Soc. Am. 104, 39-55 (1998).

${ }^{38}$ P. H. Rogers, "Electroacoustic devices," in The Electrical Engineering Handbook, Second Edition, edited by Richard C. Dorf (CRC Press, Boca Raton, FL, 1997), Chap. 46, pp. 1147-1153. 